\title{
RESPONSABILIDADE CIVIL DO MÉDICO POR ERROS OCASIONADOS NO USO DA INTELIGÊNCIA ARTIFICIAL
}

\author{
Alexandre Pereira Bonna* \\ Victória Vasconcelos Sá**
}

\section{RESUMO}

Este trabalho tem como objetivo abordar a responsabilidade civil do médico por erros ocasionados no uso da Inteligência Artificial (IA). É um artigo científico, oriundo de uma pesquisa das posições doutrinárias sobre o assunto, tendo sido analisados sobretudo artigos científicos. Analisou-se, a partir de exemplos da aplicação crescente da IA, e da legislação incidente sobre a responsabilidade civil médica, os requisitos para configurar o dever de indenizar, tendo sido compreendido que o médico não deve ser responsabilizado de forma objetiva pelos erros ocasionados no uso da IA, o que emana a necessidade de buscar-se, em alguns casos, outros responsáveis.

Palavras-chave: Inteligência Artificial; Erro Médico; Responsabilidade Civil; Legislação Incidente; Culpa Stricto Sensu.

\section{DOCTOR'S CIVIL RESPONSIBILITY FOR ERRORS OCCASIONED IN THE USE OF ARTIFICIAL INTELLIGENCE}

\begin{abstract}
This work aims to address the medical tort law for errors caused by use of Artificial Intelligence (AI). It is a scientific article, derived from a research about this subject, have been analyzeds mainly scientific articles. Based on examples about the growing application of AI, and the legislation on medical tort law, it was analyzed the requirements for configuring the duty to indemnify, and it was understood that the physician must not be blamed objective liability for the errors caused in the use of AI, which emanates the need to seek, in some cases, other responsible persons.
\end{abstract}

Keywords: Artificial Intelligence; Medical Error; Tort Law; Incident Legislation; Guilt stricto sensu.

\section{INTRODUÇÃO}

\footnotetext{
* Doutor em Direito (UFPA/University of Edinburg). Mestre em Direito (UFPA). Professor da graduação e pós-graduação (Cesupa e FACI-WYDEN). Membro do Instituto Brasileiros de Estudos de Responsabilidade Civil (IBERC). Parecerista das Revistas Civilística, Quaestio Iuris e IBERC. Advogado-Sócio do Escritório Coelho de Souza. Site com pesquisas: https://alexandrepereira85.academia.edu/. ID Orcid: https://orcid.org/0000-0001-8772-157X. E-mail: alexandrebonna@yahoo.com.br

${ }^{* * *}$ Mestranda em Direito, Políticas Públicas e Desenvolvimento Regional Amazônico, pelo Programa de PósGraduação do Centro Universitário do Pará (CESUPA). Bacharela em Direito (CESUPA). ID Orcid: https://orcid.org/0000-0002-8617-4364. E-mail: victoriavasconcelossa@ gmail.com
} 
O Direito é um ramo que se debruça sobre inúmeras questões que nascem em decorrência da vida em sociedade e, em especial, dos conflitos nela originados, de modo que resplandece a sua função social, pois a partir das leis impõem-se sobre nós regras de obediência a fim de que não estejamos à mercê de nossos estados e instintos naturais, os quais em conflitos eternos e desenfreados nos levariam a um único resultado: o caos.

Diante deste papel fundamental que o Direito exerce, é inarredável a necessidade de que as legislações de todas as partes do mundo estejam constantemente atentas às mudanças sociais, econômicas, culturais e tecnológicas da sociedade, afinal, de nada nos servem leis arcaicas que não atendem aos anseios sociais.

Neste sentido, Paulo Nader coloca que "o Direito está em função da vida social e a sua finalidade é a de favorecer o amplo relacionamento entre as pessoas e os grupos sociais, que é uma das bases do progresso da sociedade" (NADER, 2004, p. 27).

Nessa linha, um fenômeno recente e global tem sido o uso da Inteligência Artificial (de agora em diante IA), conceituado por Schermer (2011, p. 45) apud Dadalto (2019, p. 12), como:

\begin{abstract}
Inteligência artificial é o conceito usado para descrever sistemas computacionais que são capazes de aprender a partir de suas próprias experiências e resolver problemas complexos em diferentes situações- habilidades que anteriormente pensamos ser únicas em seres humanos. Trata-se, também, de um termo guardachuva que engloba diversos tipos de 'machine learning', que pode ser definido como um conjunto de técnicas e mecanismos que permite que computadores 'pensem' ao criar algoritmos matemáticos baseados em dados acumulados.
\end{abstract}

Esta tecnologia vem sendo utilizada em diversas atividades, tais como comunicação $^{1}$, segurança pública ${ }^{2}$, indústria ${ }^{3}$, medicina ${ }^{4}$ e até mesmo no âmbito jurídico ${ }^{5}$.

\footnotetext{
${ }^{1}$ Quando abrimos algum e-mail, o serviço recomenda algumas respostas rápidas, as quais sempre combinam com o e-mail recebido. Isso ocorre em razão do uso da IA que entende o conteúdo da mensagem e cria algumas opções de respostas curtas (MULLER, 2018)

2 "Reconhecimento facial: tecnologia embutida em câmeras de segurança usa algoritmos de inteligência artificial para identificar pessoas". Em um projeto-piloto realizado no carnaval de 2019 foram efetuadas prisões de 8 pessoas com mandados de prisão no Rio de Janeiro, em razão da infraestrutura montada pela cidade que contou com 28 câmeras posicionadas pela cidade, as quais por meio da IA são capazes de identificar pessoas analisando detalhes do rosto (AGRELA, 2019).

${ }^{3}$ Há sistemas automáticos que conseguem diagnosticar doenças ou pragas em determinados tipos de plantações. Outro exemplo da aplicação da IA na indústria é o de que vários bancos ou mesmo lojas de comércio eletrônico utilizam robôs para iniciar o atendimento com o cliente, pontuando-se que inclusive estes robôs conseguem por vezes solucionar o problema, sem ser necessária a intervenção de funcionários (COMO É A APLICAÇÃO DA INTELIGÊNCIA ARTIFICIAL NA INDÚSTRIA, 2018).

${ }^{4} \mathrm{Na}$ China, clínicas de saúde fazem o atendimento completo de um paciente por volta de 1 minuto. Mais de mil doenças comuns, com seus sintomas, diagnósticos e tratamentos estão no banco de dados do software
} 
Neste enredo, no Brasil há um aumento exponencial do uso da IA para auxiliar hospitais e médicos em diversas tarefas que antes eram desempenhadas exclusivamente por seres humanos, como pode ser observado nos seguintes exemplos:

a) Um algoritmo, desenvolvido por pesquisadores do Hospital Israelita Albert Einstein com participação de pesquisadores do Laboratório de Big Data e Análise Preditiva em Saúde (Labdaps) da Universidade de São Paulo (USP), é capaz de detectar pacientes acometidos pelo novo coronavírus (COVID-19), com base em exames de sangue e informações básicas de admissão em unidades hospitalares, tendo índice de 77\% de acerto, sendo uma alternativa na triagem de casos diante da escassez de testes; (ROMANI, 2020).

b) O hospital Sírio-Libanês, localizado em São Paulo, e a Siemens Healthineers, em parceria, firmaram um acordo de cooperação de dois anos que prevê uma varredura em laudos de tomografias do tórax de pacientes do hospital, cujo objetivo é o de encontrar nódulos achados incidentalmente em exames de rotina ou consultas de emergência. Tal varredura será realizada por um software Proactive Follow-up, que vem sendo treinado para identificar nódulos pulmonares de maior risco de serem malignos. A iniciativa visa evitar a demora na identificação de câncer de pulmão e, futuramente, pretende-se usar a mesma tecnologia para identificar problemas cardíacos ou problemas de próstata, por exemplo, minimizando a demora de um diagnóstico. Importante pontuar que o Sírio Libanês é o terceiro hospital do mundo a fazer uso deste software (PAINEL POLÍTICO, 2018);

c) O grupo Fleury- empresa de saúde brasileira-, passou a ser a primeira instituição da América Latina a oferecer um "exame diagnóstico cujo laudo é emitido com auxílio da computação cognitiva" (CAMBRICOLI, 2018, n.p.). O teste consiste no mapeamento de alterações genéticas nos tumores de pacientes que não responderam ao tratamento padrão e, a partir disso, o software faz uma espécie de rastreio de todos os estudos existentes no mundo, indicando em um laudo o tratamento com evidências de maior eficácia.

usado pela Ping An Good Doctor. O sistema identifica a doença e indica o tratamento mais adequado a partir de uma análise do quadro do paciente e em caso de necessidade de medicação, as unidades contam com 100 categorias de remédios estocados (BRETERNITZ, 2019).

5 "No ambiente judiciário, o Supremo Tribunal Federal já conta com um sistema autônomo (denominado Victor, em homenagem ao Ministro Victor Nunes Leal) apto à análise dos recursos extraordinários que chegam ao tribunal e à identificação daqueles que estão vinculados a determinados temas de repercussão geral" (TEPEDINO; SILVA, 2019, p. 15). 
Nesse espeque, a presente pesquisa se dedica a estudar o impacto da IA no campo da responsabilidade civil do médico (a), visto que as categorias clássicas para formar o dever de indenizar (culpa, nexo causal e dano) necessitam de um amadurecimento diante dessa nova realidade. Assim, no cenário atual, o $§ 4$ do art. 14 do CDC estabelece que "a responsabilidade pessoal dos profissionais liberais será apurada mediante a verificação de culpa", dispositivo este que traz imbróglio no tocante ao dever de indenizar do médico por erro da IA utilizada, pois poder-se-ia utilizar como argumento o fato de o erro ter sido da IA e não pessoal do médico (BRASIL, 1990).

De outro lado, a partir de uma ótica da vítima, é evidente que a relação pacientemédico é marcada pela vulnerabilidade do primeiro (art. 4, I, do CDC) e, numa análise introdutória, seria possível inferir que eventuais erros da IA estariam dentro do risco inerente a atividade do médico e por isso, se encaixaria na responsabilidade objetiva do mesmo (Art. 927, p.u, CC/2002) (BRASIL, 2002, n.p.).

\footnotetext{
Art. $4^{\circ}$ A Política Nacional das Relações de Consumo tem por objetivo o atendimento das necessidades dos consumidores, o respeito à sua dignidade, saúde e segurança, a proteção de seus interesses econômicos, a melhoria da sua qualidade de vida, bem como a transparência e harmonia das relações de consumo, atendidos os seguintes princípios:

I - reconhecimento da vulnerabilidade do consumidor no mercado de consumo; [...]

Art. 927. Aquele que, por ato ilícito (arts. 186 e 187), causar dano a outrem, fica obrigado a repará-lo.
}

Contudo, o grande desafio reside no fato de que o material que o (a) jurista deve analisar precisa estar contido na ordem jurídica brasileira, pois são estes comandos normativos que regulam a vida da sociedade, como o Código Civil de 2002, o Código de Defesa do Consumidor e a Constituição Federal de 1988.

Diante deste cenário, a pesquisa tem como questão básica: "quais os requisitos para configurar a responsabilidade civil do médico por danos causados no uso da IA?"'. Como questões secundárias, tem-se: a) Conceito e aplicação da IA na área médica; b) quais os diplomas normativos que incidem no caso? c) requisitos para configurar o dever de indenizar?

A relevância do presente trabalho está no fato de que embora não seja uma realidade a existência de demandas por indenizações originadas por erro no uso da IA, é fundamental pensar nos institutos jurídicos sobre a responsabilidade civil, haja vista que 
uma das maiores tendências da medicina é o uso da IA. Nesse sentido, invariavelmente surgirão conflitos e danos envolvendo pacientes e médicos que utilizarão a IA.

A método da pesquisa é o hipotético-dedutivo, pois a partir de categorias mais gerais a abstratas, buscará chegar em conclusões mais específicas. A metodologia na questão da cronologia, será da seguinte forma: a) primeiramente, a pesquisa analisará a relação do médico com a IA a partir das seguintes obras DADALTO, Luciana; PIMENTEL, William. Responsabilidade civil do médico no uso da inteligência artificial. Revista IBERC, Minas Gerais, v.2, n. 3, p. 5, set./dez.2019; TEPEDINO, Gustavo; SILVA, Rodrigo da Guia. Desafios da Inteligência Artificial em matéria de responsabilidade civil. Revista Brasileira de Direito Civil, set/2019; b) em seguida, investigará os diplomas normativos que incidem no caso de danos causados no uso de IA; c) por fim, tendo como base o referencial teórico supramencionado, buscará sintetizar os requisitos para configurar o dever de indenizar do médico.

\section{CONCEITO E APLICAÇÃO DA IA NA ÁREA MÉDICA}

Inicialmente, antes de adentrarmos nos institutos jurídicos sobre a responsabilidade civil médica por erros ocasionados pela IA, é imprescindível compreendermos de forma mais sólida o que é a IA e quais suas aplicações nos dias atuais na área médica.

De acordo com Azeredo (2014, p. 23-28, apud Tepedino e Silva, 2019, p. 63), “A inteligência artificial é usualmente compreendida a partir de características como autonomia, habilidade social, cooperação, proatividade e reatividade”. É que uma vez que:

[...] as máquinas e softwares aperfeiçoam o desenvolvimento cognitivo humano, acumulando experiências próprias e extraindo delas aprendizados - se torna possível que robôs inteligentes ajam de forma independente e tomem decisões de forma autônoma. Nessa perspectiva, em que há uma maior preocupação com casos em que a máquina ou sistema se torne autossuficiente [...] (ALBIANI, 2019, p. 12).

Tepedido e Silva (2019, p. 02-03), em suas brilhantes pontuações, nos esclarecem que não é de hoje que se vislumbram temáticas relacionadas à aplicação da IA, mas, pelo 
contrário, o imaginário popular sempre foi alimentado, por debates sobre as repercussões da IA nas relações sociais por meio de livros e filmes, por exemplo.

A partir disso, referidos autores (TEPEDINO; SILVA, 2019, p. 04), expõem que:

Entre tantas reflexões que essas obras suscitam, pode-se destacar uma característica presente na generalidade das representações artísticas daquilo que se imaginava como a vida do futuro: a existência de seres, com maior ou menor grau de autonomia, capazes de interagir com o ambiente e com outros (humanos ou não) e, ao fim, extrair aprendizados de suas próprias experiências. [grifo nosso].

Nos deparamos então com o ponto central do que é a IA, que tem como característica basilar justamente a capacidade de, a partir de suas próprias experiências, gerar aprendizados e tomar decisões independentes a partir desse autoaprendizado e autoaperfeiçoamento.

Neste sentido, Peter Bock (1988, p. 33-52 apud DADALTO; PIMENTEL, 2019, p. 5):

\begin{abstract}
A inteligência artificial não tem uma definição pré-estabelecida, contudo, sugere uma hipótese ao dizer que a programação de uma máquina, com regras detalhadas, para a aplicação de conhecimento específico, permitindo que este sistema apreenda as regras com base na interação de tentativa e erro com o ambiente. [grifo nosso].
\end{abstract}

Diante de tais pressupostos, podemos avançar no que se refere à aplicação da IA na área médica nos dias atuais, devendo ser ressaltado desde já a necessidade de os setores públicos e privados investirem cada vez mais nessas tecnologias, visto que "o principal objetivo de um sistema inteligente é buscar a solução de problemas, facilitando o desenvolvimento de atividades humanas" (DADALTO; PIMENTEL, 2019, p. 05).

$\mathrm{Na}$ área da saúde, os sistemas inteligentes retratam esses benefícios, como em cirurgias:

É possível, por exemplo, que um sistema dotado de inteligência gere imagens em terceira dimensão (3D) e indiquem ao médico anormalidades, tornando a ação menos invasiva possível. Todavia, importante destacar, que esses sistemas ainda estão longe de serem autônomos, por isso dependem da ação de um médico, que, por exemplo, através de um braço robótico, realiza uma cirurgia. Os dados gerados durante as operações são posteriormente utilizados pelo próprio sistema para melhorar sua atuação nos procedimentos subsequentes. Esse tipo de operação, além de ser menos invasiva, também reduz o tempo médio de recuperação dos pacientes, diminuindo os custos do procedimento. (STONE et al, 2010, p. 28 apud DADALTO; PIMENTEL, 2019, p. 05, grifo nosso) 
Outro exemplo prático da aplicação da IA na área da saúde, foi a instalação de scanners termais nas estações de trens de cidades da China visando identificar febre em passageiros que ali atravessavam. O propósito dessa ação era o de monitorar os passageiros acometidos pela Covid-19 (novo coronavírus) e, assim, controlar a expansão da pandemia. Ademais, além dessa importante tecnologia, a companhia dinamarquesa UVD Robots firmou acordo com a Sunay Healthcare Suplly para distribuir seus robôs para hospitais chineses, os quais andam pelas alas hospitalares, desinfetando-as, usando luz UV (MATSU, 2020).

Alicerçado ao que vem sendo falado aqui, é de extrema relevância o esclarecimento de que ao falar-se em IA, nos deparamos com o que se chama de Machine Learning e Deep Learning, surgindo a necessidade de conceituar e diferenciar essas expressões.

Ambos os termos acima expostos são formas de IA, uma vez que esta pode ser vista como um termo genérico (QUAIS AS DIFERENÇAS ENTRE MACHINE LEARNING E DEEP LEARNING, 2020), todavia, são formas de IA distintas. Ou seja, IA é gênero, do qual são espécies o Machine Learning e o Deep Learning.

Sobre isso, Andreas Matthias (2004) apud Tepedido e Silva (2019, p. 03) expõe que "a complexidade dos sistemas dotados de inteligência artificial incrementa-se exponencialmente a partir dos modelos de Machine Learning (aprendizado de máquina), caracterizados pela aptidão da máquina a adquirir aprendizado a partir das suas próprias experiências".

Caso se verifique, ainda, a utilização de modelos baseados em redes neurais à semelhança do funcionamento do cérebro humano, alude-se, no estágio mais atual da evolução tecnológica, ao Deep Learning (aprendizado profundo) (TEPEDINO; SILVA, 2019, p. 04).

Em complemento a tais conceitos, Lecun et a.l (2015 apud Schmidt et al., 2018, p.2), registram que a tecnologia de Machine Learning (aprendizado de máquina) vem sendo utilizada em diversas áreas, dentre elas, negócios, ciência e medicina:

Os autores relatam que Machine Learning tem aprimorado pesquisas realizadas na internet, recomendações de amizades nas redes sociais e predição de texto em smartphones. Sistemas utilizando Machine Learning também estão sendo usados, com alto grau de precisão, para identificação automatizada de objetos em 
imagens, processamento de linguagem natural e reconhecimento de padrões. Dentre as técnicas de aprendizado de máquina, os algoritmos de Deep Learning (Aprendizagem Profunda) demonstram grandes avanços na extração automatizada de representações com vários níveis de abstração a partir de dados complexos e são, portanto, aplicáveis a diferentes domínios da ciência. Tais algoritmos são capazes de detectar correlações existentes entre variáveis que não estão aparentemente visíveis, possibilitando indicar um padrão não observado quando as variáveis são analisadas isoladamente [LeCun et al. 2015]. Nesse contexto, o campo de Health Informatics (Informática em Saúde) tem alcançado perspectivas importantes com a utilização de Big Data. Novas possibilidades de obter e registrar dados como Registros Eletrônicos de Saúde (RES), sensores eletrônicos e dispositivos móveis, em conjunto com técnicas de Aprendizado de Máquina, estão tornando possível o aprimoramento de diagnósticos e predições, qualificando o tratamento e reduzindo custos (SCHMIDT et al, 2018, p. 02, grifo nosso)

A partir deste viés, Schmidt et al (2018) expõem, em sua pesquisa, que referidas técnicas de IA, em especial a de Deep Learning vêm trazendo importantes contribuições para a área médica, sendo aplicada na predição de mortalidade em Unidades de Terapia Intensiva.

Diante de tais ensinamentos, é possível depreender-se que evidentemente a IA tem sido utilizada para auxiliar diversos setores da sociedade e, em especial, o setor médico, de modo que sua utilização ao proporcionar o aprimoramento de diagnósticos e predições, serve como um suporte de decisões clínicas, sendo de extrema relevância os resultados promissores do uso da IA na área médica quando vem a tornar um procedimento menos invasivo ou diminuir o tempo de recuperação do paciente.

Por fim, partindo do pressuposto de que o uso da IA terá crescimento exponencial na área médica, faz-se necessário refletir sobre os parâmetros para a formação do dever de indenizar na hipótese de o uso da IA causar dano ao paciente, haja vista que a relação do médico com essa tecnologia é recente e ainda desperta imbróglios conceituais e jurídicos, os quais serão expostos nos tópicos seguintes.

\section{DIPLOMAS NORMATIVOS NOS DANOS CAUSADOS NO USO DA IA}

Conforme alhures delineado, a utilização da IA cada vez mais está presente em nosso dia a dia e suas aplicações no âmbito médico vêm tornando premente a necessidade de que haja a adoção de medidas para a regulação dessa atividade. Neste ínterim, devemos ter em vista que "a aplicação da tecnologia é um dos motivos para a necessária evolução da teoria da responsabilidade civil, que gera respostas jurídicas novas também para os médicos" (DADALTO, PIMENTEL, 2019, p. 12). 
Diante da evidência de que "o uso dos sistemas inteligentes possibilita o surgimento de novos problemas justamente por sua autonomia e capacidade de aprendizado, pois a regra geral é a de que a responsabilidade civil é atribuída a quem lhe der causa" (DADALTO; PIMENTEL, 2019, p. 14), surge o questionamento sobre quem deve recair a responsabilidade civil decorrente do uso da IA, isto é, se é sobre a própria IA (o que ocasionaria a necessidade de seguros), do fabricante, do fornecedor ou de quem a utiliza. Porém, antes de enfrentar este ponto, é imprescindível que se compreenda como se dá a responsabilidade civil na seara médica e sobre quais dispositivos legais essa se fundamenta, haja vista que para lançar reflexões mais aprofundadas diante de novas realidades (IA), primeiramente faz-se necessário o estudo da base normativa acerca da responsabilidade civil médica.

Atualmente o instituto da responsabilidade civil está consubstanciado no Código Civil, o qual prevê que (BRASIL, 2002, n.p.):

\footnotetext{
Art. 186. Aquele que, por ação ou omissão voluntária, negligência ou imprudência, violar direito e causar dano a outrem, ainda que exclusivamente moral, comete ato ilícito.

Art. 187. Também comete ato ilícito o titular de um direito que, ao exercê-lo, excede manifestamente os limites impostos pelo seu fim econômico ou social, pela boa-fé ou pelos bons costumes.

Art. 927. Aquele que, por ato ilícito causar dano a outrem, fica obrigado a repará-lo. .

Parágrafo único. Haverá obrigação de reparar o dano, independentemente de culpa, nos casos especificados em lei, ou quando a atividade normalmente desenvolvida pelo autor do dano implicar, por sua natureza, risco para os direitos de outrem. [grifo nosso]
}

Assim, a partir da premissa de que quem comete um ato ilícito deve repará-lo, é necessário tecer diferenciação no que se refere ao regime da responsabilidade civil, isto é, quando este é objetivo e quando é subjetivo.

Para a professora Regina Beatriz Tavares da Silva (2002, p. 820 apud NUNES, 2011, n.p.), "o novo Código Civil, ao regular a responsabilidade civil, alarga a aplicação da responsabilidade objetiva, com a adoção da teoria do risco criado, mas mantém o sistema vigente de que a regra geral é a responsabilidade subjetiva".

De forma complementar, Tartuce (2011, p. 411, apud FERREIRA, 2014, n.p.) coloca que, "conforme a teoria subjetiva - doutrina tradicionalmente majoritária -, a culpa genérica ou lato sensu constitui, em regra, elemento necessário da conduta humana para que se crie a obrigação de reparar o dano causado". 
Neste sentido, Moniz Pereira (2016, 8 pp., apud FERREIRA, 2016, p. 42) explicam que a culpa no campo da responsabilidade civil “é tomada não no seu sentido psicanalítico referido a pulsões internas, mas antes na culpa existencial”.

Imperioso destacar, neste viés, que alicerçado à culpa deve haver um efetivo dano passível de reparação que instale a necessidade de "restauração do status quo ante" (INÁCIO, 2017, n.p.).

Em contrapartida, como exceção vigora a responsabilidade objetiva, na qual "o elemento culpa é absolutamente desprezado, pois bastará ao lesado provar o nexo de causalidade entre o dano que experimentou e ato do agente que o causou para fazer surgir a obrigação de indenizar" (NUNES, 2011, n.p.).

Nesse diapasão, Luis Fernando Rabelo Chacon (2009, p. 8, apud PRETEL, 2010, n.p.) disserta que:

\begin{abstract}
O sistema subsidiário, de exceção, é aquele embasado na teoria do risco, que não exige a culpa do agente como elemento formador do dever de indenizar. Haverá responsabilidade civil objetiva quando a lei assim determinar (exemplo: art. 14 do CDC, art. 37 da CF, art. 933 do CC, etc) ou quando a atividade habitual do agente implicar risco para outrem (exemplo: atividades industriais de produção química, fábrica de explosivos, etc), ou seja, derivada da exploração de atividade que repute risco ao direito de outrem. Então, ao lado da teoria da culpa da responsabilidade civil subjetiva, encontramos a teoria do risco para embasar a responsabilidade civil objetiva. Pode-se afirmar que quando a lei determina expressamente que seja a responsabilidade objetiva aplicada em determinado caso o faz porque reconhece naquela circunstância a presença pontual do risco aos direitos de outrem ou o desequilíbrio entre as partes envolvidas, o que exige intervenção.
\end{abstract}

Deste modo, verifica-se que na legislação civil brasileira, a regra que permeia o instituto da responsabilidade civil é o regime subjetivo, o qual "depende da existência de dolo (intenção) ou culpa (negligência, imprudência ou imperícia) por parte do agente causador do dano. No caso de erro médico, o paciente tem que provar a culpa do médico que o assistiu" (NASCIMENTO, 2017, n.p.).

Neste enredo, leciona Miguel Kfouri Neto, citando Zelmo Denari (2001, p. 192, apud PRETEL, 2010, n.p.):

\footnotetext{
Os médicos e advogados - para citarmos alguns dos mais conhecidos profissionais - são contratados ou constituídos com base na confiança que inspiram aos respectivos clientes. Assim sendo, somente serão responsabilizados por danos quando ficar demonstrada a ocorrência da culpa subjetiva, em quaisquer das suas modalidades: negligência, imprudência ou imperícia.
} 
Sobre isso, versa o artigo $14, \S 4^{\circ}$ do CDC, o qual leciona que:

\begin{abstract}
Art. 14. O fornecedor de serviços responde, independentemente da existência de culpa, pela reparação dos danos causados aos consumidores por defeitos relativos à prestação dos serviços, bem como por informações insuficientes ou inadequadas sobre sua fruição e riscos.

[...]

$\S 4^{\circ}$ A responsabilidade pessoal dos profissionais liberais será apurada mediante a verificação de culpa. (BRASIL, 1990, n.p.).
\end{abstract}

Relacionado ao suscitado, outro ponto a ser averiguado no que tange a responsabilidade civil médica é o que se refere a responsabilidade de meio e de resultado.

Neste espeque, Maria Helena Diniz (2019, p. 76, apud COELHO, 2020, n.p) entende que obrigação de meio "é aquela em que o devedor se obriga tão somente a usar de prudência e diligência normais na prestação de certo serviço para atingir um resultado, sem, contudo, se vincular a obtê-lo".

De outro lado, obrigação de resultado, conforme também leciona Maria Helena Diniz (2019, p. 123, apud COELHO, 2020), seria "aquela em que o credor tem o direito de exigir do devedor a produção de um resultado, sem o que se terá o inadimplemento da relação obrigacional. Tem em vista o resultado em si mesmo, de tal modo que a obrigação somente se considerará cumprida com a efetiva produção do resultado pretendido."

Neste mesmo viés, Kfouri Neto (2011, p. 189) apud Coelho (2020) pontua que "a regra geral dita que o médico não pode obrigar-se, no desempenho de sua atividade profissional, a obter resultado determinado acerca da cura do doente e assumir o compromisso de reabilitar sua saúde."

Todavia, uma vez que a responsabilidade de meio, conforme disposto, é entendida como regra, esta naturalmente comporta exceções. É que há certas especialidades em que o médico além de agir com toda a diligência possível, está vinculado a atingir determinado resultado. Sobre isso, vejamos:

Só é possível admitir a aplicação da responsabilidade objetiva quando a atividade profissional buscar resultado determinado, ou seja, atividade fim. No Brasil, tal teoria tem sido aplicada nos casos de cirurgias estéticas, conhecidas como cirurgias-plásticas. Nos demais casos, a atividade do médico é de meio, uma vez que tal profissional compromete-se a usar todas as regras e os métodos de sua profissão para recuperar a saúde do paciente que lhe é submetido a tratamento (INÁCIO, 2017, n.p.). 
Cumpre salientar, ainda, que será necessário avaliar, em se tratando de cirurgião plástico, se a cirurgia é 'estética' ou 'reparadora', pois no primeiro caso a responsabilidade será objetiva, haja vista que a obrigação será de resultado, contudo, no caso de ser 'reparadora', a responsabilidade recairá na regra geral, ou seja, será subjetiva, uma vez que a obrigação será de meio e não de fim (SILVA, 2019, n.p.).

Diante do acima exposto, faz-se imprescindível salientar que na relação médicopaciente incide o Código de Defesa do Consumidor, primeiro porque o paciente se enquadra como consumidor, uma vez que a busca por um tratamento é entendida como a busca por um serviço (art. $2^{\circ}$ do CDC), segundo porque se evidencia a vulnerabilidade do paciente:

[...] visto que, nas relações hospitalares, caracteriza-se como um consumidor e, perante o médico, é igualmente vulnerável, pois confia sua vida e integridade física e psíquica aos cuidados do profissional, confiando em seu conhecimento técnico e acreditando que seu direito à saúde será resguardado com seriedade e eficiência (OTERO, 2019, p. 27).

E, de outra banda, a figura do médico se encaixa como fornecedor de serviços (art. $3^{\circ}$ do CDC) (INÁCIO, 2017, n.p.).

Todavia, importa salientar, conforme acima delineado, que "embora seja fornecedor, o profissional liberal, em regra, responde pela ilicitude de seus atos por meio da comprovação de culpa - regra geral adotada no direito civil brasileiro - tal como previsto expressamente no $\S 4^{\circ}$ do artigo 14 do Código de Defesa do Consumidor” (INÁCIO, 2017, n.p.).

Contudo, "a responsabilidade subjetiva do médico (CDC, artigo $14, \S 4^{\circ}$ ) não exclui a possibilidade de inversão do ônus da prova, se presentes os requisitos do artigo $6^{\circ}$, VIII, do CDC, devendo o profissional demonstrar ter agido com respeito às orientações técnicas aplicáveis" (TRENTIM, 2019, n.p.).

Delineado tal cenário, acerca dos comandos normativos incidentes sobre a responsabilidade civil médica, progredimos à análise de como estes são aplicados no que tange a IA.

\section{REQUISITOS PARA CONFIGURAR O DEVER DE INDENIZAR DO MÉDICO}


Após delinearmos qual a legislação incidente sobre a responsabilidade civil médica, a questão que passa a nos nortear é: “em quais hipóteses o médico poderia ser responsabilizado por danos causados a partir do uso de IA e, quando não for possível responsabilizá-lo, seria adequado buscar outros obrigados a indenizar?"

Pois bem. Decerto que há incontáveis hipóteses em que é possível vislumbrar uma conduta culposa por parte do médico, entretanto, diante dos mais variados casos concretos que podem causar imbróglio, a fim de não recairmos em um "indesejável casuísmo" (SOUZA, 2013, p. 16), faz-se necessário ter por esclarecido inicialmente quais os requisitos para configurar o dever de indenizar do médico, o que é propriamente a culpa médica e como esta pode se caracterizar no uso da IA.

Conforme alhures demonstrado, a responsabilidade civil do médico, via de regra, tem natureza subjetiva, de modo que deve restar demonstrado se o profissional agiu com culpa, isto é, se agiu com negligência, imprudência ou imperícia. Pontua-se, neste sentido, que a negligência se caracteriza pela ausência de atenção/ cuidado; a imperícia pela inexperiência/ falta de conhecimentos práticos indispensáveis; e, a imprudência, pela ausência de cautela.

Ato contínuo, destaca-se que "a culpa na responsabilidade civil do profissional de saúde costuma ser materializada na figura do denominado erro médico [...]" (SOUZA, 2013, p. 17). Porém, neste viés, merece destaque o entendimento de Eduardo Nunes de Souza ao dispor que o erro médico não deve equivaler à culpa, pois a análise do erro consistiria apenas em apontar se a conduta médica adotada foi diferente de conduta diversa que talvez não teria ocasionado aquele dano, mesmo que ambas as condutas envolvessem tratamentos possíveis e cabíveis (SOUZA, 2013).

À título de exemplo, imaginemos que um médico recebe um paciente em seu consultório e o mesmo relata que vêm sofrendo fortes enxaquecas. Após alguns exames, o médico então pode receitar o medicamento ' $\mathrm{X}$ ' ou ' $\mathrm{Y}$ ', ambos permitidos e frequentemente indicados para este problema, de modo que o médico opta em receitar a medicação ' $\mathrm{X}$ ', porém ao invés de melhorar o quadro do paciente, acaba por agravar as enxaquecas.

Diante deste cenário, indaga-se: Seria crível que o médico, mesmo tendo agido de forma diligente, tendo receitado medicamento permitido cientificamente, seja responsabilizado pelo dano causado ao paciente? Decerto que isso não seria legítimo, restando evidenciado que erro médico não deve ser tido como sinônimo de culpa, de modo 
que "a responsabilidade do médico deve depender apenas da demonstração desta última" (SOUZA, 2013, p. 20).

Adélia Silva da Costa esclarece que "essa culpa deve ser aferida em sentido lato, ou seja, culpa stricto sensu e dolo [...] diante disso, pode-se concluir que a responsabilidade civil médica tem três pressupostos: a conduta culposa de um agente, a existência de um dano e a relação de causalidade entre aquela conduta e o dano" (COSTA, 2003, p. 08).

Frente à tais definições, cumpre pontuar que com o constante avanço da medicina não é mais possível tentar listar de forma taxativa quais situações em que o médico deverá ou não ser responsabilizado. Naturalmente que há situações onde o cabimento da atribuição de responsabilidade ao profissional da saúde é praticamente evidente, como "nas hipóteses de grave imperícia ou negligência- aquelas encontradiças em textos clássicos, tais como o instrumento cirúrgico deixado no interior do corpo do paciente, ou o erro crasso no diagnóstico de enfermidade muito comum [...]" (SOUZA, 2013, p. 21-22).

Entretanto, atinente às pontuações de Eduardo Nunes de Souza devemos ter em vista que "o futuro da responsabilidade civil do médico parece residir na previsão, não mais de deveres taxativos ou de hipóteses de erro médico [...], mas de procedimentos-padrão capazes de determinar a legitimidade da atuação médica [...]” (SOUZA, 2013, p. 22), indicando como fatores a serem levados em consideração:

\footnotetext{
i) o estado da arte da ciência médica, no que tange ao procedimento, terapia, exame ou conduta adotados; ii) as normas éticas atinentes à profissão e aos princípios da bioética; e iii) o respeito à autonomia existencial hoje reconhecida ao paciente, exercida por meio de escolhas baseadas no intercâmbio de informações com o médico (SOUZA, 2013, p. 22).
}

A partir de tais premissas, e já tendo sido demonstrado alhures que a IA têm tido seu uso crescente nos mais diversos ramos, dentre eles na medicina, passamos então a nos ater de que modo a referida culpa médica pode se manifestar no uso da IA para finalmente compreender se o médico pode/deve ser responsabilizado pelos eventuais erros ocasionados por estas tecnologias.

Silva e Nogaroli (2020, n.p.) abordam de forma impecável a temática, suscitando o uso da IA como suporte nas decisões médicas nos tempos da pandemia do Novo Coronavírus vivenciada, porém destacam que em que pese os benefícios trazidos pelo uso da IA como apoio clínico, e mesmo diante da eficiência de um software, estes possuem sua margem de imprecisão ao dar, por exemplo, um diagnóstico. 
Diante disso, os autores expõem a possibilidade deste software vir a apontar eventualmente um quadro diagnóstico diverso do que o médico apontou, como no caso de o médico chegar à conclusão de que o paciente estava acometido com a Covid-19 e a IA concluir que não. Em vista disso, caso o médico ignorasse seu próprio ponto de vista e acatasse a conclusão da IA de forma irrefletida, poderia vir a causar danos irremediáveis ao paciente, o qual não receberia o tratamento específico no momento devido, o que poderia acarretar a responsabilidade civil do médico pelos danos que viessem a se concretizar:

Imaginando-se a hipótese de o software apontar para um quadro diagnóstico de COVID-19, incumbirá ao profissional, ao menos, levar tal cenário em consideração, dentro das suas concretas possibilidades, antes de concluir por descartar com segurança o resultado da inteligência artificial. Neste sentido, a falta de diligência do médico ao descartar irrefletidamente o resultado obtido pela inteligência artificial poderá constituir um critério para a sua responsabilização (SILVA; NAGAROLI, 2020, n.p.).

Os autores prosseguem explicando que, o erro de diagnóstico, por si só, não teria o condão de atribuir responsabilidade ao médico sobre o dano, mas precisaria ser averiguado se o médico acatou ou não o diagnóstico da IA com base em critérios seguros:

\footnotetext{
Partindo-se de tais percepções para uma tentativa de responder aos questionamentos aventados acima, parece razoável afirmar que o médico apenas será responsabilizado por erro de diagnóstico se não houver justificativas plausíveis que o tenham levado a desconsiderar o resultado diagnóstico indicado pela inteligência artificial.

Imaginando-se a hipótese de o software apontar para um quadro diagnóstico de COVID-19, incumbirá ao profissional, ao menos, levar tal cenário em consideração, dentro das suas concretas possibilidades, antes de concluir por descartar com segurança o resultado da inteligência artificial. Neste sentido, a falta de diligência do médico ao descartar irrefletidamente o resultado obtido pela inteligência artificial poderá constituir um critério para a sua responsabilização. $[\ldots]$

Em ambos os casos supracitados, havendo divergência entre o diagnóstico clínico inicial e o resultado do dispositivo inteligente, afigura-se prudente que a decisão do médico - de seguir ou de desconsiderar a IA para concluir o seu diagnóstico seja acompanhada da prévia realização de exames laboratoriais complementares e, a depender do caso, de uma confirmação com seus pares, inclusive a distância (teleinterconsulta) (SILVA, NAGAROLI, 2020, n. p.).
}

Um outro exemplo, relacionado à como um médico pode incorrer em culpa no uso da IA, é referente aos robôs domésticos cuidadores de idosos. Neste sentido, uma empresa Japonesa (SoftBank Robotics) criou um desses robôs, o qual "já é utilizado em casas de repousos na Inglaterra. Ele conversa com o paciente e monitora a sua saúde emocional, 
repassando algumas informações aos médicos e à equipe de saúde" (NAGAROLI, 2019, n.p).

Diante disso, imaginemos que essa tecnologia forneça ao médico informações oriundas desse monitoramento em relação a um determinado idoso, o qual sofre de depressão. Suponhamos que essas informações exprimam que o idoso não teve qualquer quadro agravante no último mês relacionado à sua doença, e que o médico então decida, por meio do resultado desse monitoramento da IA, que o idoso não precisará mais fazer o uso das medicações destinadas à depressão.

Neste hipotético enredo, caso o idoso viesse a cometer suicídio, propomos a seguinte reflexão: seria cabível a responsabilidade do médico pelo ocorrido? Recorrendo inicialmente às lições dispostas no exemplo anterior, compreendemos que não seria legítimo que o médico fosse responsabilizado pelo dano de forma objetiva, de modo que seria necessário avaliar se a atuação deste foi prudente e segura, para somente então auferir se houve falha na sua atuação.

Uma das questões que poderiam ser analisadas, seria se o profissional da saúde, antes de suspender a medicação, veio, por exemplo, a fazer uma consulta com o idoso, e/ou recorreu a outros meios para atestar a mudança repentina no estado psicológico do paciente, o que demonstraria cautela. Caso contrário, se o (a) médico (a) simplesmente acatou de forma irrefletida as informações da IA, e suspendeu a medicação até então tão indispensável para tratar o quadro clínico do idoso, sem, contudo, recorrer a outros meios, a fim de se certificar de forma segura sobre a alteração da situação real do paciente, poderíamos estar diante da conclusão de que caberia a responsabilização civil do profissional pelo ocorrido.

Assim, de modo geral, entende-se que "caso a atuação do profissional revele o cuidado razoavelmente exigível na sua conduta" (BONACÚL, 2020, n.p.), este não viria a ser responsabilizado pelos erros ocasionados pela IA, o que remete à regra geral vigente em nosso ordenamento jurídico no que tange a responsabilidade civil do médico ser, via de regra, subjetiva.

Entretanto, deve-se ter em vista que não é porque a IA detém a capacidade de ser autônoma, que o médico estará sempre imune à responsabilidade pelos eventuais danos que essas tecnologias venham a causar, pois, pelo menos na atual realidade brasileira no uso da IA na seara médica, o uso desta tecnologia não se dá ainda de forma totalmente 
independente do direcionamento médico, de modo que "a decisão final sempre será do médico, que por sua vez deverá atuar com zelo, e pautado na máxima capacidade profissional" (BONACÚL 2020, n.p.).

Neste sentido, também concluíram Rodrigo da Guia Silva e Rafaella Nogaroli ao destacarem que:

[...] a decisão final segue sob o controle (e sob a responsabilidade) do profissional da saúde. Dessa conclusão não se há de extrair, porém, uma banalização da responsabilização pessoal do médico. Seguindo a tônica do momento atual, devese socorrer da prudência também para a valoração da conduta do médico em eventual demanda indenizatória. Pode-se, assim, construir bases sólidas para a rejeição de demandas frívolas, evitando-se a difusão de uma postura de medicina defensiva [...] (SILVA, NAGAROLI, 2020, n.p).

A partir disso, infere-se que, no atual contexto, onde não há ainda regulação específica sobre o uso da IA no Brasil, a solução que em nosso entendimento, seguindo os pressupostos doutrinários expostos no decorrer deste trabalho, se revela mais adequada nos casos envolvendo o manejo da IA na seara médica, é a de que, nos casos em que se faça necessária a apuração da eventual responsabilização do médico, seja analisado primeiramente se este profissional agiu com a diligência necessária que exige sua profissão ou se agiu com negligência, imprudência ou imperícia, que são os requisitos dispostos em nossa atual legislação para apuração da responsabilidade civil do médico ( $\$ 4$ do art. 14 do CDC).

Frente à tais preceitos, entende-se que pelo menos nos parâmetros atuais não seria possível que o médico seja responsabilizado objetivamente pelo erro ocasionado pela IA, pois isso seria uma solução não amparada pela legislação existente, uma vez que como demonstrado no tópico anterior deste trabalho, o (a) médico (a) somente deve ser responsabilizado (a) objetivamente nos casos em que sua obrigação seja a de atingir um resultado específico.

Diante deste entendimento, destacamos as pontuações de Christiane Albiane, no sentido de que "a responsabilidade civil objetiva em decorrência do seu uso, inevitavelmente acabará recaindo, pelo menos num momento anterior à regulação específica do tema, sobre o empresário que a produz e aufere lucros, com fundamento no risco da atividade" (ALBIANI, 2019, p. 09): 
[...] a responsabilidade civil objetiva em decorrência do seu uso, inevitavelmente acabará recaindo, pelo menos num momento anterior à regulação específica do tema, sobre o empresário que a produz e aufere lucros, com fundamento no risco da atividade. É evidente que a opção pela responsabilização objetiva, quando levada ao extremo, acarreta um desestímulo ao desenvolvimento tecnológico, científico e à inovação. [...] Esse risco se mostra ainda mais evidente quando a máquina age de maneira autônoma, independente, sem interferência e/ou controle externo, desenvolvendo novos comandos não contidos na sua programação original, já que seu comportamento deixa de ser previsível, impossibilitando a prevenção de danos. Vale ressaltar que, se em face do empresário seria possível aplicar a teoria do risco, o mesmo não ocorre quanto ao programador, já que este só poderia ser responsabilizado subjetivamente (por ser profissional liberal), ou seja, quando comprovada a ocorrência de falha na programação ou que havia previsibilidade quanto à conduta lesiva (ainda que não programada) [...]. [grifo nosso] (ALBIANI, 2019, p. 09).

Assim, diante deste cenário, compreendemos que enquanto não haja regulação específica sobre o tema, a solução que se revela mais razoável e possível de acordo com a legislação vigente, é a de que um paciente que sofra quaisquer danos causados por erros médicos no uso da IA, caso não reste demonstrado na apuração do caso concreto que houve culpa por parte do (a) médico (a), busque eventuais reparações civis perante àquele que produz e aufere lucros com a IA.

Neste viés, destaca-se ainda a Resolução do Parlamento Europeu editada em 2017, a qual "em seu texto dispõe, pelo contexto jurídico atual, a informação de que 'os fabricantes, os operadores, os proprietários ou os utilizadores poderiam ser considerados estritamente responsáveis pelas ações ou omissões de um robô', devido a não possibilidade de punir as máquinas pelos seus atos pela falta de personalidade" (DADALTO; PIMENTEL, 2019, p. 12).

Imperioso ressaltar que há inúmeros caminhos a serem destrinchados no que se refere ao uso da IA, como a necessidade ou não de atribuir à essas tecnologias personalidade jurídica, que é um dos temas inclusive suscitados na mencionada Resolução do Parlamento Europeu de 2017; a questão em torno da criação de seguros obrigatórios para a IA; e, conforme outrora falado, a padronização de procedimentos específicos a partir de direcionamentos emitidos pela comunidade científica no manejo da IA pelos profissionais da saúde, tendo como fundamento que a:

[...] atribuição da responsabilidade ao médico deve ser o descumprimento de um conceito normativo de culpa, objetivamente aferível a partir do descumprimento de procedimentos padronizados, sensíveis à confiança naturalmente despertada na sociedade pelo exercício de uma profissão liberal, mas concebidos de modo a não se exigir do médico onisciência ou infalibilidade sobre-humanas, e sim a 
diligência e perícia legitimamente esperáveis pelo paciente e pela sociedade (SOUZA, 2013, p. 22).

Diante de todo o exposto, ainda que eventualmente ocorram problemas gerados pelo uso da IA, é certo que estes não devem servir de empecilho para a firmação destas tecnologias em prol da sociedade, visto a potencial capacidade desses sistemas inteligentes em gerar inúmeros benefícios nos mais diversos ramos, e em especial na seara médica, à exemplo do auxílio aos profissionais da saúde, seja em diagnósticos, tratamentos, cirurgias ou consultas, cujo principal objetivo a ser visado é a melhoria da prestação do serviço médico como forma de valorizar o elemento mais valioso e vital de todos: a saúde.

\section{CONSIDERAÇÕES FINAIS}

Compreendemos, no presente trabalho, que para que se atribua ao (a) médico (a) a responsabilização civil por um eventual erro decorrente do uso da IA, é preciso partir-se da regra geral prevista em nosso ordenamento jurídico, o qual estabelece que a responsabilidade civil deste profissional é subjetiva, o que nos leva a concluir que nos casos envolvendo a IA, deve ser analisado se o médico agiu com a diligência necessária que exige sua profissão ou se agiu com negligência, imprudência ou imperícia, que são os requisitos dispostos em nossa atual legislação para apuração da responsabilidade civil do médico.

Diante disso, caso reste caracterizada a culpa stricto sensu, conclui-se que será então devida sua responsabilização civil pelo erro ocasionado pela IA. Entretanto, enquanto não há uma regulação específica sobre tal tema, entendemos que quando não for cabível que o médico seja responsabilizado pelos erros ocasionados pela IA, resta ao paciente buscar eventual reparação civil perante àquele que produz e aufere lucros com a IA.

Porém, é necessário que o assunto proposto seja enfrentado pelos estudiosos do Direito e pelo legislador, devendo ser analisado, por exemplo, a necessidade ou não de atribuir à essas tecnologias personalidade jurídica; a questão em torno da criação de seguros obrigatórios para a IA; e, a padronização de procedimentos específicos a partir de direcionamentos emitidos pela comunidade científica no manejo da IA pelos profissionais da saúde.

\section{REFERÊNCIAS}


AGRELA, Lucas. Inteligência artificial começa a chegar à segurança pública. Exame, 2019. Disponível em: 10/07/2019 em https://exame.abril.com.br/tecnologia/inteligenciaartificial-comeca-a-chegar-a-seguranca-publica/. Acesso em: 19 abr. 2020.

ALBIANI, Christine. Responsabilidade Civil e Inteligência artificial: Quem responde pelos danos causados por robôs inteligentes? Disponível em: https://itsrio.org/wpcontent/uploads/2019/03/Christine-Albiani.pdf. Acesso em 20 abr. 2020.

BRASIL. Decreto- Lei $\mathrm{n}^{\mathrm{o}}$ 10.406, de 10 de janeiro de 2002- Código Civil. Disponível em: http://www.planalto.gov.br/ccivil_03/leis/2002/110406.htm, Acesso em 20 de junho de 2020.

BRASIL, Lei $\mathrm{n}^{\mathrm{o}}$ 8.078, de 11 de setembro de 1990. Código de Defesa do Consumidor. Disponível em: http://www.planalto.gov.br/ccivil_03/leis/18078.htm, Acesso em: 15 jul. 2020.

BRETERNITZ, Vivaldo. China radicaliza o uso de inteligência artificial na medicina. Crypto, 2019. Disponível em: em: < https://cryptoid.com.br/inteligencia-artificial/chinaradicaliza-o-uso-de-inteligencia-artificial-na-medicina/> Acesso em: 03 mai. 2020.

BONÁCUL, Alexandre. A responsabilidade civil médica nos casos de inteligência artificial. Campo Grande News, 2020. Disponível em: https://www.campograndenews.com.br/artigos/a-responsabilidade-civil-medica-nos-casosda-inteligencia-artificial Acesso em: 07 ago. 2020.

COELHO, Natalia Bacaro. A obrigação de meio e de resultado do médico. Migalhas, 2020. Disponível em: https://www.migalhas.com.br/depeso/318760/a-obrigacao-de-meio-ede-resultado-do-medico. Acesso em: 28 jun. 2020.

COMO É A APLICAÇÃO DA INTELIGÊNCIA ARTIFICIAL NA INDÚSTRIA. A voz da indústria, 2018. Disponível em: 17/09/2018 em: https://avozdaindustria.com.br/indstria-40-totvs/como-aplica-o-da-intelig-ncia-artificial-na-ind-stria. Acesso em: 19 abr. 2020.

COSTA, Adélia Silva da. Responsabilidade Civil Médica. Rev. Fund. Esc. Super. Minist. Público Dist. Fed. Territ., Brasília, Ano 11, Edição Especial, p. 07-49, set. 2003.

DADALTO, Luciana; PIMENTEL, William. Responsabilidade civil do médico no uso da inteligência artificial. Revista IBERC, Minas Gerais, v.2, n. 3, p. 12, set./dez.2019. Acesso em 15 jul. 2020.

FERREIRA, Ana Elizabeth. Responsabilidade civil extracontratual por danos causados por robôs autônomos. Revista portuguesa do dano corporal (27), 2016, p. 42. Acesso em: 21 jun. 2020.

FERREIRA, Osiel. Responsabilidade civil subjetiva e responsabilidade civil objetiva. Jus, 2018 (elaborado em 2014). Disponível em: 
https://jus.com.br/artigos/64351/responsabilidade-civil-subjetiva-e-responsabilidade-civilobjetiva. Acesso em: 21 jun. 2020.

INÁCIO, Jone. A responsabilidade civil do médico: visão sob o código civil e o código de defesa do consumidor. Âmbito Jurídico, 2017. Disponível em: https://ambitojuridico.com.br/edicoes/revista-164/a-responsabilidade-civil-do-medicovisao-sob-o-codigo-civil-e-o-codigo-de-defesa-do-consumidor/. Acesso em: 21 jun. 2020.

MATSU, Carla. Como a tecnologia está sendo usada para entender e combater o novo Coronavírus. Computerworld, 2020. Disponível em: https://computerworld.com.br/2020/03/11/como-a-tecnologia-esta-sendo-usada-paraentender-e-combater-o-novo-coronavirus/. Acesso em: 01 jun. 2020.

MULLER, Leo. 6 coisas que a Google faz com inteligência artificial e você nem percebe. Tecmundo, 2018. Disponível em: 26/12/2018 em https://www.tecmundo.com.br/software/129980-6-coisas-google-inteligencia-artificialvoce-percebe.htm. Acesso em: 19 abr. 2020.

NADER, Paulo. Introdução ao estudo do direito. 24 ed. Rio de Janeiro: Forense, 2004.

NASCIMENTO, Gisele. Responsabilidade civil do médico à luz do código de defesa do consumidor. Migalhas, 2017. Disponível em: https://www.migalhas.com.br/depeso/269480/responsabilidade-civil-do-medico-a-luz-docodigo-de-defesa-do-consumidor. Acesso em: 21 jun. 2020.

NOGAROLI, Rafaella. Implicações ético jurídicas da medicina robótica e inteligência artificial nas cirurgias e cuidados na saúde. Disponível em: https://academiamedica.com.br/blog/implicacoes-etico-juridicas-da-medicina-robotica-einteligencia-artificial-nas-cirurgias-e-cuidados-da-saude\#!\#_edn32. Acesso em: 21 ago. 2020 .

NUNES, Marcelo Porpino. O regime da responsabilidade civil no novo código civil. Migalhas, 2011. Disponível em: https://www.migalhas.com.br/depeso/126063/o-regimede-responsabilidade-civil-no-novo-codigo-civil. Acesso em: 21 jun. 2020.

OTERO, Cleber Sanfelici; ARDUINI, Tamara Simão. A vulnerabilidade do paciente e a responsabilidade civil advinda de danos morais e existenciais ocasionados na relação triangular entre pacientes, médicos e hospitais. Revista Eletrônica do Curso de Direito da UFSM, Santa Maria, RS, v. 14, n. 3, e32681, set./dez. 2019. ISSN 1981-3694. Disponível em: https://periodicos.ufsm.br/revistadireito/article/view/32681 Acesso em: 15 jul. /2020.

PAINEL POLÍTICO, 2018. Inteligência artificial será usada para mapear risco de câncer de pulmão. Disponível em: $<$ https://painelpolitico.com/inteligencia-artificial-serausada-para-mapear-risco-de-cancer-de-pulmao/> Acesso em: 08 ago. 2020.

PRETEL, Mariana. Da responsabilidade civil do médico- a culpa e o dever de informação. OAB, 2010.2 Disponível em: 
http://www.oabsp.org.br/subs/santoanastacio/institucional/artigos/da-responsabilidadecivil-do-medico-2013-a-culpa-e. Acesso em: 21 jun. 2020.

QUAIS AS DIFERENÇAS ENTRE MACHINE LEARNING E DEEP LEARNING?, Lecom, 2020. Disponível em: https://www.lecom.com.br/blog/machine-learning-e-deeplearning/. Acesso em: 01/06/2020.

ROMANI, Bruno. Einstein e USP criam inteligência artificial para Covid-19. Terra, 2020. Disponível em: https:/www.terra.com.br/noticias/coronavirus/einstein-e-usp-criaminteligencia-artificial-para-covid-19,c6a65f79cf18b62eb24c7690497dc6f8v71dtq1g.html.

Acesso em: 02 mai. 2020.

SCHMIDT, Diogo; DA SILVA, Denise Bandeira; DA COSTA, Cristiano André; RIGHI, Rodrigo da Rosa. Um Modelo de Predição de Mortalidade em Unidades de Terapia Intensiva Baseado em Deep Learning. In: ANAIS PRINCIPAIS DO SIMPÓSIO BRASILEIRO DE COMPUTAÇÃO APLICADA À SAÚDE (SBCAS), 18. , 2018, Natal. Anais Principais do XVIII Simpósio Brasileiro de Computação Aplicada à Saúde. Porto Alegre: Sociedade Brasileira de Computação, july 2018.

SILVA, Eduardo C. Defesa Jurídica do cirurgião plástico. Migalhas, 2019. Disponível em: https://www.migalhas.com.br/depeso/300122/defesa-juridica-do-cirurgiao-plastico. Acesso em: 28 jun. 2020.

SOUZA, Eduardo Nunes de. Do erro à culpa na responsabilidade civil do médico. civilistica. com: revista eletrônica de direito civil, v. 2, n. 2, p. 1-27, 2013.

SILVA, Rodrigo da Guia; NOGAROLI, Rafaella. Inteligência artificial na análise diagnóstica da Covid-19: possíveis repercussões sobre a responsabilidade civil do médico. Migalhas, 2020. Disponível em: < https://www.migalhas.com.br/coluna/migalhaspatrimoniais/322941/inteligencia-artificial-na-analise-diagnostica-da-covid-19-possiveisrepercussoes-sobre-a-responsabilidade-civil-do-medico Acesso em: 07 ago. 2020.

TEPEDINO, Gustavo; SILVA, Rodrigo da Guia. Desafios da Inteligência Artificial em matéria de responsabilidade civil. Revista Brasileira de Direito Civil, 2019.

TRENTIM, Erika Gonçalves Pastorelli. Erro Médico na Cirurgia Plástica Responsabilidade Subjetiva do Cirurgião Plástico-Obrigação de Meio. Âmbito Jurídico, 2019. Disponível em: https://ambitojuridico.com.br/cadernos/direito-civil/erro-medico-nacirurgia-plastica-responsabilidade-subjetiva-do-cirurgiao-plastico-obrigacao-de-meio/ Acesso em: 24 ago. 2020. 